
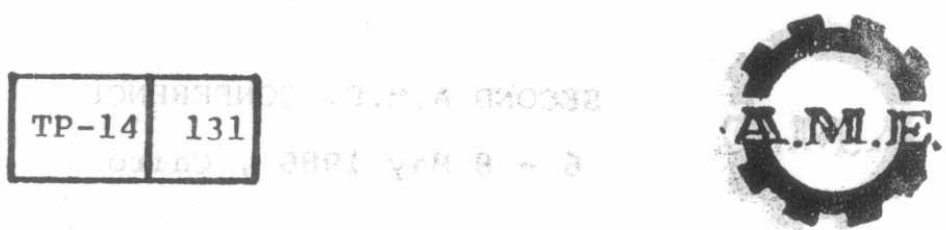

MILITARY TECHNICAL COLLEGE

CAIRO - EGYPT

\title{
MATHEMATICAL OPTIMIZATION VERSUS SIMULATION FOR THE SELECTION OF CUTTING PARAMETERS FOR C.A.M.
}

BY

Dr. Soad M. Serag

\section{ABSTRACT}

- This paper investigates the feasibility of applying mathematical - programming and heuristic simclation algorithms for the optimal selection of cutting fiarameters in $M / C$ tools.

Recently, this problem has tecome of major interest to researchers working in the area of Computer $A$ ided Manufacturing $(C . M . M)$. The concepts anc methods developed in this paper are very useful for the produclion engineers and can be successfully applied for semi-autcmatic and automatic machine tool production centres as well as lumerically Controlled $\mathrm{M} / \mathrm{C}$ Tools or direct numerically controlled $\mathrm{M} / \mathrm{C}$ centres (DNC) and FMS.

\section{INTRODUCTION}

The optimal choice of cuttinc paranntors had always been an intercsting subject ror the poluction engineers. With the rapid development of producticn systems and the development of Numerically controlled $\mathrm{M} / \mathrm{C}$ tocls to direct numerically controlled $M / C$ tools by centeral computers (DNC) and the advent of DNC with automatic transfer known as Flexible Manufacturing systems : (FMS) (1), the choice of cutting parameters become a continious

The machining process in the new Machine centers involves multiple machining processes. Thus the choice of cutting parameters
becomes a more difficult problcm.

In the following study we will. consider two possible approaches to solve the problem, the. first one is to use mathematical optimization techniques and the second one is to develop a simulation Heuristic Algorithm the properties of optimal solution and

Associate Professor, Próduction Engg. \& Machine Design Dept., Faculty of Engineering \& Technology, Menoufia University,
Shebin El-Kom, EGYPT. 
the special nature of the problem.

The study will focus on the two main machining processes used in the new development $M / C$ centers, namely the turning and Milling operations.

The study is divided into two sections, the first

- section formulates the various machining problems and develops

- the concept of multiple-process. In the second section the: solution of the machining model by mathematical programming . and simulation is discussed.

\section{PROBLEM FORMULATION}

The selection of optimal cutting parameters can be solved as a programming problem, the production engineer aims to optimize a given objective and satisfy the relevent constraints in cutting.

The function that the engineer wants to optimize, known as objective function or effectiveness or performance index (2): must be defined and it varies according to the goals, in our study we will take the total cutting (varlable) costs. $C_{t}$

$$
\begin{aligned}
& C_{t}=C_{1}\left[T_{C}+C_{2} \cdot \frac{T_{C}}{T}\right] \\
& C_{t}-\text { Total cutting cost, } \\
& C_{1}-\text { Total Machining time cost, } \\
& C_{2}-\text { Total cost coefficient, } \\
& T_{s}=\frac{L}{F \cdot N}, \\
& T_{C}-\text { Cutting time, } \\
& F-\text { Feed/rev., } \\
& N-\text { Rev. per Min., } N=\frac{12 . V_{C}}{\pi D} \\
& L-\text { Cutting Length, } \\
& V_{C}-\text { Cutting Velocity (Ft/Min), }
\end{aligned}
$$




\section{\begin{tabular}{|l|l|}
\hline TP-14 & 133
\end{tabular}}

$T-$ Tool life $=\frac{k}{v^{1 / n} \cdot F^{1 / n_{1}} \cdot d^{1 / n_{2}}}$

d - depth of cut,

$k, n, n_{1}, n_{2}$ - Constant For Modified Taylor equation,

T - Tool life (Minutes).

The performance index as defined by (1) - will always take the form:

$$
\begin{aligned}
& c_{\text {to }}=k_{o l} \cdot F^{-1} \cdot v^{-1}+k_{02} \cdot v^{a o} \cdot F^{b o} \cdot d^{c o} \\
& F, v, d \text { decision variables. }
\end{aligned}
$$

The values of the decision variables in (2) are subjected to various types of constraints:-

- Machine Constraints:

Such as speed ranges and feed ranges and Max. Power:-

(Feed range) $\quad F_{L} \leq F \leq F_{u}$

(Speed range) $\mathrm{N}_{\mathrm{L}} \leq \mathrm{N}$

(Max. Power) $\quad \mathrm{P} \leq \mathrm{P}_{\mathrm{U}}$

- Surface Roughness Requirement:

Specially in Finishing operation.

- Limitation For Max. Cutting Force:

Due to Tool or W.P. deflection limits.

All the above constraints can generally be stated as:-

$$
L(i) \leq k_{i} \cdot v^{a i} \cdot F^{b i} \cdot d^{c i} \leq U(i)
$$

$i$ - indicate constraint (i),

ai,bi,ci = Constants for constraints (i),

$L(i), U(i)$ - Lower and upper bounds for cutting operation constraints.

The Turning Process:-

Using expressions (2) and (3) for the turning process. 
$\Gamma$ Performance index:

$c_{\text {to }}=C_{10} \cdot\left(\frac{L \pi D}{12}\right) \cdot v^{-1} \cdot F^{-1}+C_{20}\left(t_{0} \frac{L \pi D}{12 k}\right) d^{1 / n 2} \cdot v^{\left(\frac{1}{n}-1\right)} \cdot F^{\left(\frac{1}{n I}-1\right)}+$

$C_{30}\left(\frac{L \pi D}{12 k}\right) d^{1 / n 2} \cdot v^{\left(\frac{1}{n}-1\right)} \cdot F^{\left(\frac{1}{n I}-1\right)}$

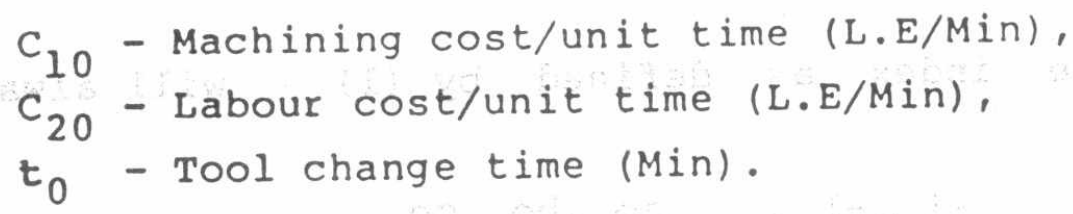

\section{Constraints:-}

$\begin{array}{ll}1-\text { depth of cut } & d \leq U_{1} \\ 2-\text { Power } & k_{2} \cdot V \cdot F^{b 2} \cdot d \leq U_{2} \\ 3-\text { Force } & k_{3} \cdot F^{b 3} \cdot d \leq U_{3} \\ 4-\text { Feed } & L_{4} \leq F \leq U_{4} \\ 5-\text { Finish } & \frac{F 2}{8 R} \leq U_{S} \\ & \text { (R-Tool radius) }\end{array}$

As an example consider (3) the rough cutting by H.S.S. Tool where the constants are ${ }^{(3)}:-$

:

$$
\begin{aligned}
& \frac{1}{n}=6.67, \frac{1}{n 1}=2.8, \frac{1}{n 2}=0.93 \\
& \mathrm{~K}=4.3772 \times 10^{11} \mathrm{~L}=10 \mathrm{in}, \mathrm{D}=2 \mathrm{in} \\
& C_{\text {O3 }}=2.64 \quad \text { L.E. } \\
& C_{\mathrm{O} 2}=0.107 \quad \text { L.E. } / \mathrm{Min} \text {. } \\
& C_{\text {Ol }}=0.151 \text { L.E./Min. } \\
& t_{0}=2 \text { Min. }, k_{2}=20, k_{3}=143895 \\
& \text { Max. Power }=U_{2}=0.75 \quad \mathrm{~K} . \mathrm{W} \\
& \text { Max Force }=U_{3}=1501 \mathrm{~b} \text {. } \\
& b_{2}=b_{3}=0.8, u_{1}=0.05 \text { in, } u_{4}=0.02, L_{4}=0.002 \\
& c_{\text {to }}=0.791 \mathrm{~F}^{-1} \cdot \mathrm{V}^{-1}+6.542 \times 10^{-10} \mathrm{~d}^{0.93} \cdot \mathrm{v}^{5} \cdot 67 . \mathrm{F}^{1.80} \\
& d \leq 0.05 \\
& 20 \mathrm{VF}^{0.8} \cdot \mathrm{d} \leq 0.75 \\
& 143895 F^{0.8} \cdot d \leq 150
\end{aligned}
$$


The Milling Process:-

The following variations are met in the Milling process:-

a) D - diameter of Milling cutter is decision variable,

b) $\mathrm{S}_{z}$ - feed per tooth $\frac{\mathrm{F}}{\mathrm{Z}}$, and $\mathrm{Z}$ is a decision variable,

c) B - width of cutter (or work piece) may, or may not be a decesion variable.

$$
T_{c}=\frac{L}{S_{z} \cdot Z \cdot N}=\left(\frac{L \pi}{I 2}\right) \frac{D}{S_{z} \cdot Z \cdot V}
$$

The extended tool life formula is:-

$$
V \cdot T^{n} \cdot d^{n 1} \cdot S_{z}^{n 2} \cdot B^{n 3} \cdot D^{n 4}=K
$$

Using $(7,8)$ we develop the following performance index

$$
\begin{aligned}
c_{\text {to }}= & c_{10}\left(\frac{L \pi}{12}\right) D \cdot v^{1} \cdot s_{z}^{-1} \cdot z^{-1}+\left(\frac{c_{20} \cdot t_{0} \cdot L \cdot \pi}{12 k}\right) v^{\frac{1}{n}-1} \cdot d^{\frac{n_{1}}{n}} \cdot s_{z}\left(\frac{n_{2}}{n}-1\right) \\
& \cdot B^{\frac{n_{3}}{n}} \cdot D\left(\frac{n_{4}}{n}+1\right) \cdot z^{-1}+\left(\frac{c_{30}}{12 k} \cdot L \pi\right) v^{\frac{1}{n}-1} \cdot d^{\frac{n_{1}}{n}} \cdot s_{z}\left(\frac{n_{2}}{n}-1\right) \cdot B^{\frac{n_{3}}{n}} \cdot D^{\left(\frac{n}{n}+1\right)} \cdot z^{-1}
\end{aligned}
$$

and the following constraints:-

depth of cut :

$$
\mathrm{d} \leq \mathrm{U}_{\mathrm{l}}
$$

Power

$$
: k_{2} \cdot d^{a 2} \cdot s_{z}^{b 2} \cdot B^{c 2} \cdot D^{d 2} \cdot z \cdot v \leq u_{2}
$$

Force

Finish

$$
: k_{2} \cdot d^{a 2} \cdot s_{z}^{b 2} \cdot B^{c 2} \cdot D^{d 2} \cdot z \leq u_{3}
$$

$$
\frac{C \cdot s^{2} \cdot z^{2}}{4 D}
$$

$$
C=1.5
$$$$
\leq \mathrm{U}_{4} \quad \ldots \ldots
$$

Speed range : $L_{5} \leq\left(\frac{12}{\pi}\right) \cdot V \cdot D^{-1}$

Feed range $\quad: L_{6} \leq \mathrm{S}_{z} \cdot \mathrm{Z}$

$$
\begin{aligned}
& \leq U_{5} \\
& \leq U_{6}
\end{aligned}
$$

Consider the case of peipheral Milling with carbide tools (4)

$$
\begin{aligned}
& k=20.1 \quad n=0.6 \quad n_{1}=0.1 \quad n_{2}=0.75 \quad n_{3}=0.2 \quad n_{4}=-0.2 \\
& k_{2}=1.262 \quad, a_{2}=1, b_{2}=0.75, c_{2}=1.1 \\
& \mathrm{~d}_{2}=-0.2 \\
& k_{3}=43200 \\
& u_{1}=1 \quad U_{2}=6, U_{3}=435, U_{4}=0.002
\end{aligned}
$$


\begin{tabular}{|l|l|}
\hline $\mathrm{TP}-14$ & 136 \\
\hline
\end{tabular}

5

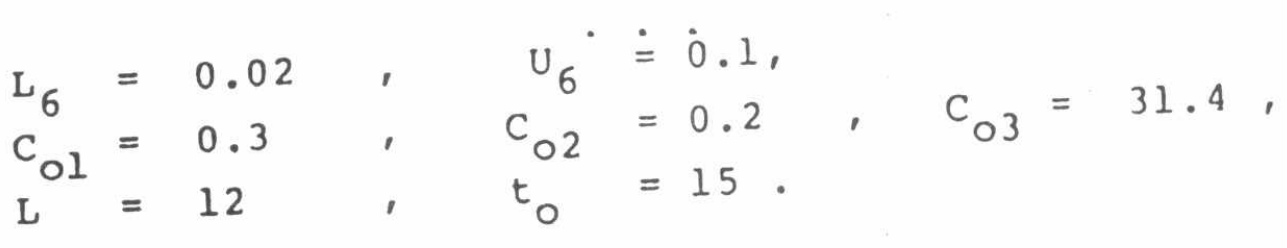

Minimize

$c_{t_{0}}=0.9372 \mathrm{~s}^{-1} \mathrm{v}^{-1} \mathrm{D}_{2}{ }^{-1}+5.373 \mathrm{v}^{0.66} \mathrm{~d}^{0.16} \mathrm{~s}_{\mathrm{z}}{ }^{0.25} \cdot \mathrm{B}^{0.33} \mathrm{D}^{0.67} \mathrm{z}^{-1}$

Subject to:-

depth of cut : $-d_{1} \leq 0.5$

Power : $-1.262 \mathrm{~d} \mathrm{~S}_{\mathrm{z}} 0.75 \mathrm{~B}^{1.1} \mathrm{D}^{-0.2} \mathrm{zV} \leq 6$

Force :- $43200 \mathrm{~d} \mathrm{~S}_{2}$

Finish : $-0.375 \mathrm{~s}_{\mathrm{z}}^{2} \mathrm{z}^{2} \mathrm{D}^{-1} \leq 0.02$

speed range : $-20 \leq 3.82 \mathrm{~V} \mathrm{D}^{-1} \leq 500$

Feed range : $-0.02 \leq \mathrm{S}_{\mathrm{z}} \mathrm{Z} \leq 0.1$

\section{Multiple Cutting Process:-}

The cutting processes discussed in sections (2.1), (2.2) are single machining processes. In the new machining technique where various tools and processes are performed in the machining. center, the situation is far more complicated.

The work-piece is machined in the "so called" machining center by several tools and operations, that can be numbered $j=1,2, \ldots, M$ - every cutting tool $j$ will perform sequence of operation $\mathrm{Nj}$, where:

$$
\sum_{j=1}^{M} N_{j}=N_{j}=N
$$

where N - Total No of operations

This means that both the performance index ( 1 ) and the contraints must be modified to an overall performance index and overall constraints set.

$$
\begin{aligned}
C_{t} & =\sum_{j=1}^{M} C_{t}(j) \\
& =\sum_{M}^{M} \quad c(i) \quad\left[T(i)+C(i) \quad T_{c}(j)\right.
\end{aligned}
$$


$\Gamma$

$$
\begin{aligned}
C_{t} & =\sum_{j=1}^{M} \frac{C_{0}(j) L \pi}{12} F^{-1} \cdot v^{-1} \cdot D+ \\
& +\sum_{j=1}^{M}\left\{\frac{C_{O 3 j} L}{12 k}+\left\{\frac{C_{O 2} j \cdot{ }^{T} \circ j \cdot{ }^{L \pi}}{12 k}\right\}\left[v_{j}^{a_{O j}} \cdot d_{j}^{b_{O j} \cdot F_{j} C_{O j} \cdot D}{ }^{d}{ }^{O j}\right]\right.
\end{aligned}
$$

Subject to:-

depth of cut :- $d_{j} \leq U_{i}(j)$

Power/Force $\quad:-L_{i j} \leq K_{i j} \cdot v_{j}^{a i j} \cdot d_{j}^{b i j} \cdot F_{j}^{c i j} \cdot D_{j}^{d i j} \leq U i j$

Finish $\quad:-K_{F j} \cdot f^{2} \cdot D^{-1} \leq U_{f(j)}$

Feed range $:-L_{F(j)} \leq F_{j} \leq U_{F(j)}$

speed range $\quad:-L_{N}(j) \leq \frac{12}{\pi} \quad D_{j}^{-1} \cdot v_{j} \leq U_{N(j)}$

$$
\begin{aligned}
& j=1,2, \ldots \ldots . M \\
& i=1,2, \ldots \ldots . R
\end{aligned}
$$
Moreover it is possible to include the total process time of
the part $\mathrm{T}_{\mathrm{p}}$ as constrained.

$$
\begin{aligned}
\mathrm{Tp}= & \sum_{j=1}^{M} \mathrm{Tp} \leq \mathrm{Tu} \\
\mathrm{Tp}= & \sum\left\{\mathrm{Tc}(j)+\delta_{j} \mathrm{t}_{\circ j}\right\} \leq \mathrm{Tu} \\
& \delta j=1 \quad \text { if } \mathrm{To}(j)>\mathrm{T} j \\
& \delta j=0 \quad \text { other-size } \\
& \text { PROBLEM SOLUTION }
\end{aligned}
$$

Solution By Mathematical Programming:

Until recently the choice of cutting parameters for single cutting operation as given in eq. $(4,5,9)$ was a difficult non-linear programming problem, however the development of geometrical programming for optimization of posynomicals and signonicals offered us a powerful tool to solve the problem. 
The algorithm stated in this work originates from the geometric programming technique of Zener (7) and developed by Blau(9) the algorithm has the following steps:-

1 - Enter problem as specified by format (correspondence between problem coef. and format coef.)

2 - Determine Initial Weight

$$
\begin{aligned}
& z=\sum_{t=1}^{T o} \sigma_{\text {ot }} C_{\text {ot }} \prod_{n=1}^{N} \times n^{\operatorname{aot} n} \\
& \mathrm{~V}=/ \mathrm{Z} / \\
& B_{n t}=c_{m t} \prod_{n=1}^{N} \times n^{a_{m t n}} \\
& m=0,1, \ldots \ldots, M
\end{aligned}
$$

3 - Calculate the vector of orthogonality condition.

$$
\begin{aligned}
& K=\left[\begin{array}{llll}
\sum_{t=1}^{T m} & \sigma_{m t} & a_{m t h} & B m t
\end{array}\right] \\
& H=\sum_{t=1}^{T O} \sigma_{\text {ot }}
\end{aligned}
$$

4 - Evaluate Initial Multiplin

$$
\begin{aligned}
Y & =\left(K^{T} K^{-1}\right) K^{T} H+ \\
K^{T} & =\text { Transpose of } K
\end{aligned}
$$

5 - If this is the first Iteration go to step 6, other-wiae determine new weight as follows:

$Y_{N E W}=Y_{\text {OLD }}+\Delta Y$

GOTO STEP 6

6 - Calculate matrix t

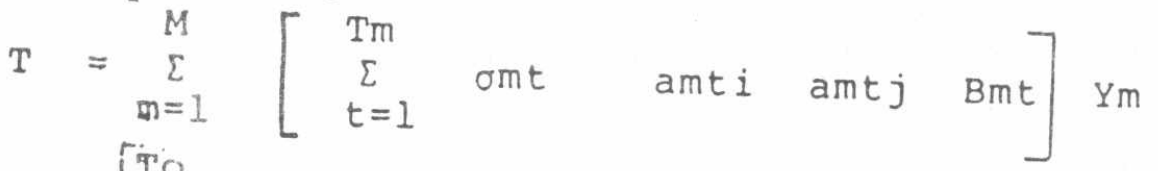

$$
\begin{aligned}
& -\left[\begin{array}{lllll}
\mathrm{TO} & \sigma \text { ot } & \text { amti } & \text { amtj } & \text { Bot } \\
t=1 & & i=1, \ldots . . N &
\end{array}\right]
\end{aligned}
$$


\begin{tabular}{l|l}
\hline TP-14 & 139
\end{tabular}

$\Gamma_{7}$ - EVAluate ERROR

8 - FORMULTE, NEWTON - RAPHSON MATRIX

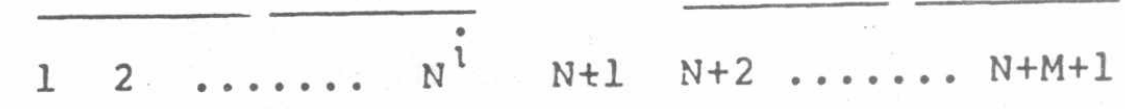

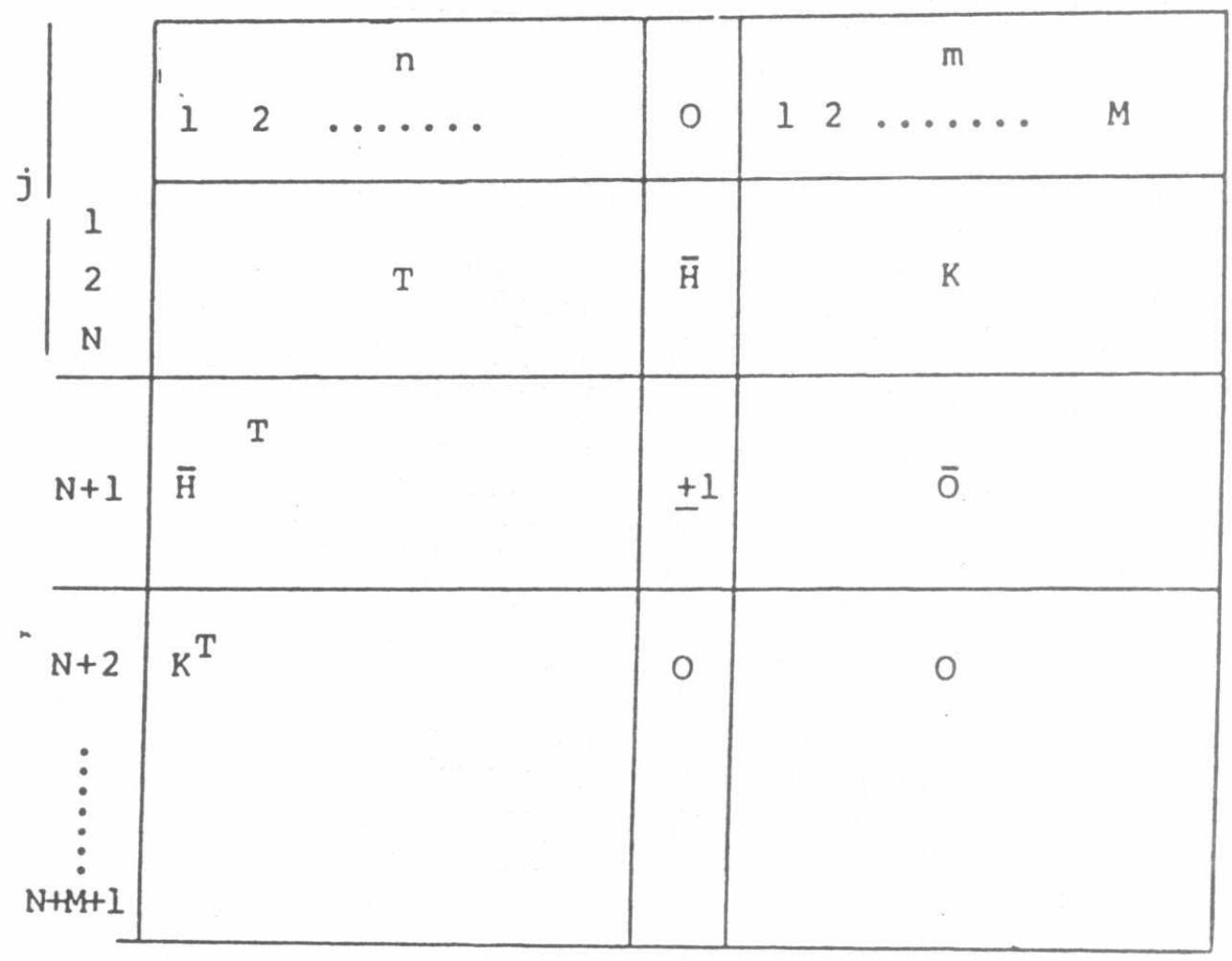

9 - INVERT MATRIX R

10 - Find VECTOR ADJUSTMENT

$$
R^{-1} e^{-}=\left[\begin{array}{rr}
\Delta \ln & \bar{X} \\
\Delta \ln & v \\
\Delta \bar{y}
\end{array}\right]
$$


11 - Calculate New Values

$$
\begin{aligned}
& \bar{x}=\bar{x} \quad \exp (\Delta \ln \bar{x}) \\
& v=v \quad \exp (\Delta \ln v)
\end{aligned}
$$

12 - has SOlUtion CONVERGED TO ACCEPtABLE LEVEL LIMIT ?

$$
\begin{aligned}
& \text { YES:- PRINT RESULTS AND STOP } \\
& \text { NO :- GO TO STEP } 13
\end{aligned}
$$

13 - MAXIMUM ALLOWABLE INTERATIONS REACHED

YES:- STOP and PRINT RESULTS

NO :- GO TO STEP 5

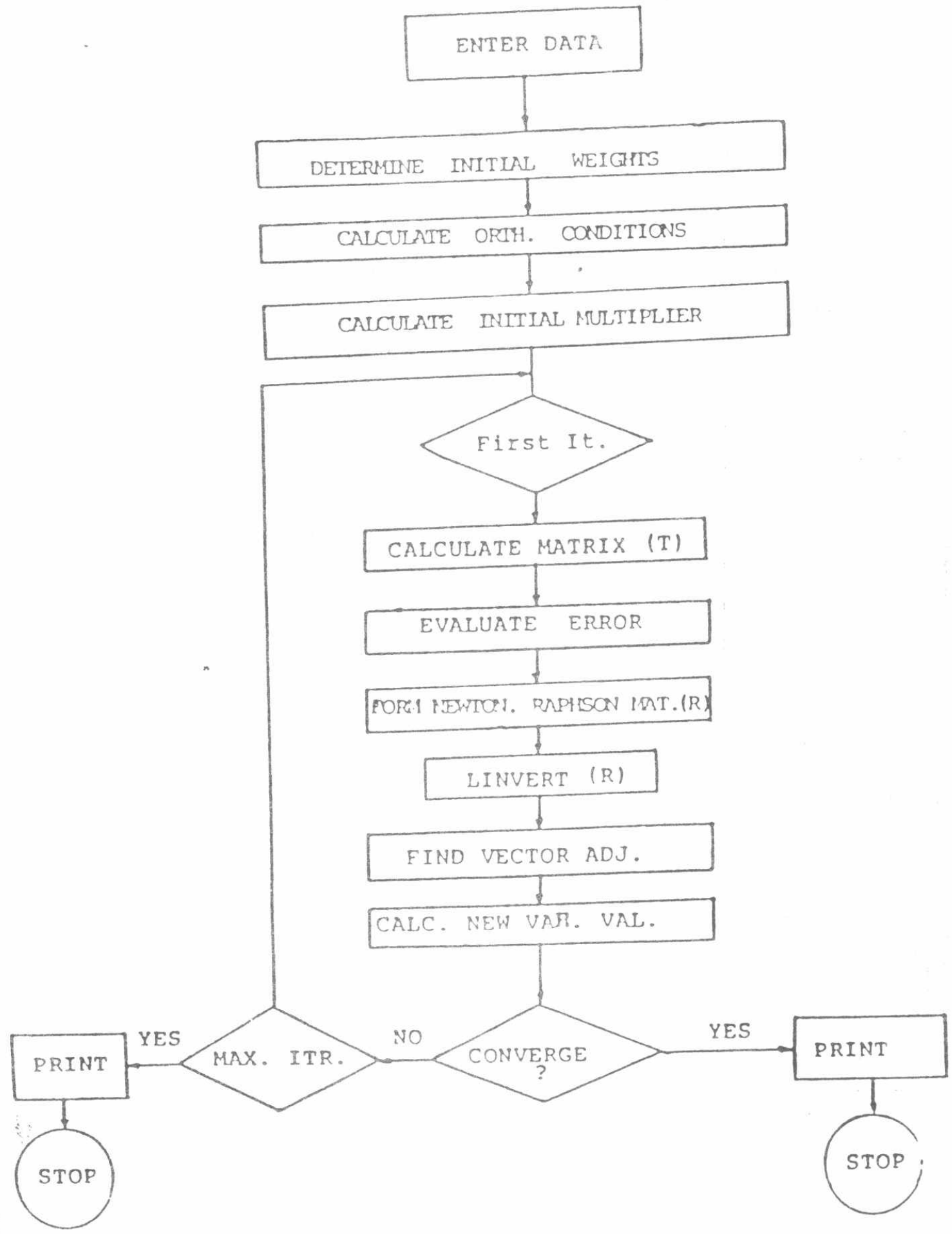




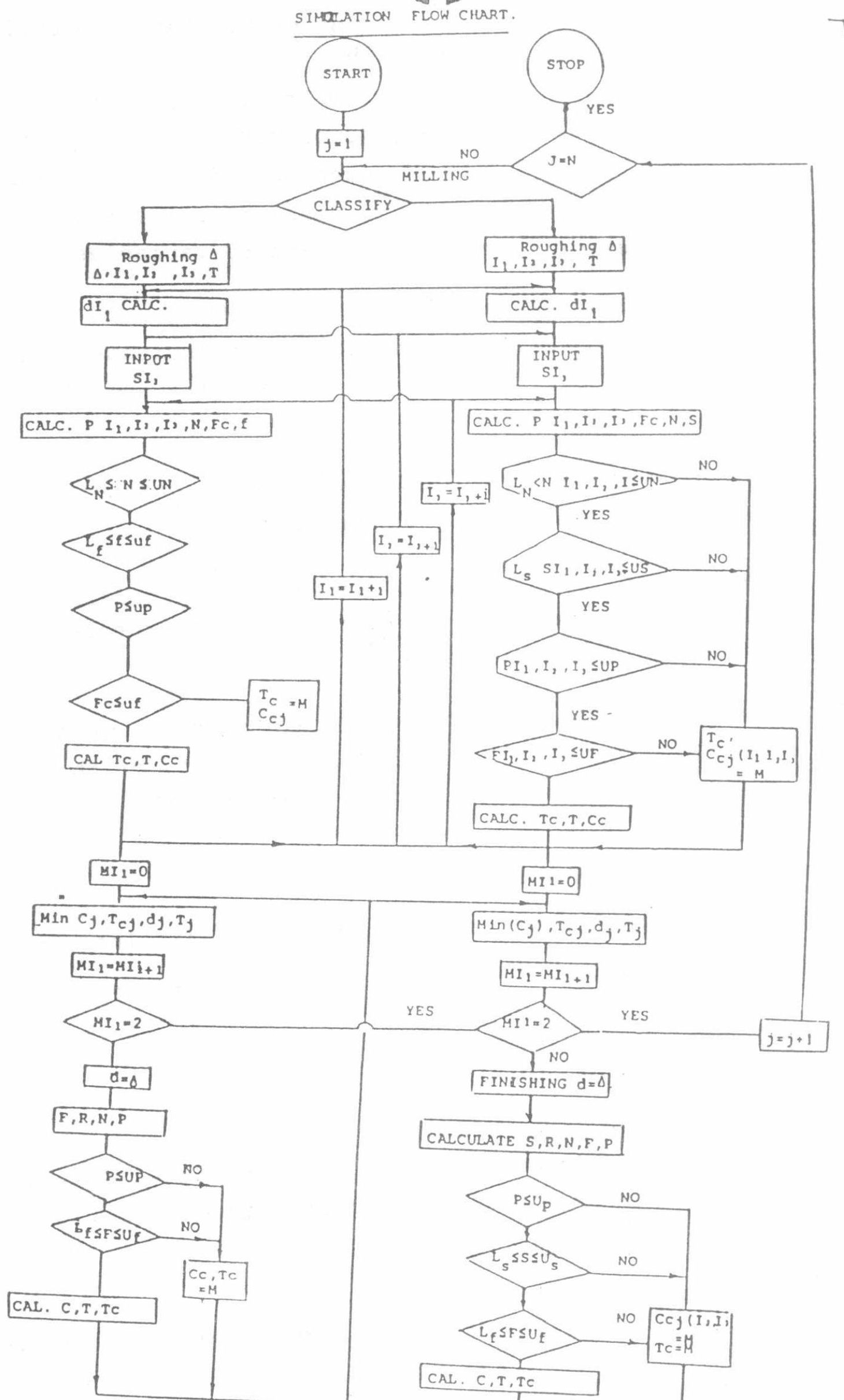




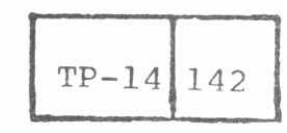

TThe following draws-backs are to be stated for the application of mathematical optimization.

1 - The size of the problem for multiple cutting operation will result in a huge number of constraints and variable. Consider the case of 10 sequences and 6 cutting variables with 5 constraints for each operation, the result will be a system of 50 constraints and 60 variables.

The resultant Matrices $T, R$ will become very large, the error for matrix inversions with increased No. of iterations will affect the computational accuracy.

2 - Another problem known as the degree of difficulty which arises with no of variables exceeding constraints, this is almost the case for our problem.

This means that also the degree of difficulty which increase for Multiple cutting - and convergence will take longer and longer times.

3 - There are many practical constraints in the metal cutting that will further increase the difficulty of the problem. For instance, in the roughing operation the no. of paths:
must be integer.

$$
\frac{\Delta}{d}=I
$$

Constraint (14) is another example for $\delta=$ Integer.

4 - In some $M / C S$ the speeds and feeds are not stepless so that

$$
\begin{aligned}
& U F \geq F \quad \geq L_{F} \\
& U N \geq \frac{12}{\pi} \quad V^{-1} \geq L_{N}
\end{aligned}
$$

Will not ensure feasible solutions. All the above remarks creates a necessity to develop and easier and more practical algorithm to solve the multiple-
cutting problem. SOLUTION BY SIMULATION

The simulation technique developed depend on the following
facts:1 - The performance indoy 
\begin{tabular}{|l|l|}
\hline $\mathrm{TP}-14$ & 143 \\
\hline
\end{tabular}

2 - Performance index is a convex function.

3 - The optimal value of the overall performance index is the sum of optimal value of single cutting problem with given constraints.

The operations were classified as turning or Millingeach operation can be either roughing or finishing.

01) The Number of paths Index $I_{1}=1,2, \ldots . R_{1}$

02) The Number of feeds Index $I_{2}=1,2, \ldots . R_{2}$

$$
R_{2}=\text { No of feeds }
$$

If $R_{2}$ is not stated - its is entered as

$$
R_{2}=\bar{R}_{2}
$$

and $F_{1}=F$ Min

$$
F_{I_{2}}=F M i n+(I 2-1)\left(\frac{F M A X-F M I N}{R_{2-1}}\right)
$$

03) The Number of Tool life iterations $\mathrm{I}_{3}$

TMin Minimum permissible life,

TMAX MAX, permissible life,

$$
\mathrm{T}_{3} \quad \mathrm{TMIN}+\left(\mathrm{I}_{3}-1\right) \frac{\mathrm{TMAX}-\mathrm{T} M I N}{\mathrm{R}_{3-1}}
$$

04) $J=$ No of Tools.

$$
J=1,2, \ldots \ldots \ldots \ldots \ldots \ldots, M
$$

\section{4 - CONCLUSION:-}

Application of both techniques for problem (6), (10) and "the multiple problem of the combined operations gives the following results:-

\begin{tabular}{|l|c|c|r|r|r|r|r|c|}
\hline \multirow{2}{*}{} & \multicolumn{4}{|c|}{ G.P } & \multicolumn{4}{c|}{ HEURISTIC } \\
\cline { 2 - 10 } & $C_{C}$ & $F, S$ & VC & $\begin{array}{c}\text { Comp. } \\
\text { Time sec }\end{array}$ & $C_{C}$ & $F, S$ & VC & $\begin{array}{c}\text { Comp. } \\
\text { Time }\end{array}$ \\
\hline Turning & 0.6327 & 0.005 & 252 & 6 & 0.643 & 0.005 & 250 & 4 \\
\hline Milling & 2.8090 & 0.075 & 131 & 1.2 & 2.953 & 0.075 & 140 & 4 \\
\hline Multiple & 3.442 & - & - & 40 & 3.596 & - & - & 16 \\
\hline
\end{tabular}

This proves the validity of Heuristic simulation tech. It should be noted that if $\mathrm{V}_{\mathrm{C}}$ is incremented $\left(\mathrm{I}_{3}\right)$ to more points 


\begin{tabular}{|l|l|}
\hline $\mathrm{TP}-14$ & 144 \\
\hline
\end{tabular}

SECOND A.M.E. CONFERENCE

6 - 8 May 1986 , Cairo

$\Gamma$

The total cost is higher in the simulation Mech. by app. $3 \%$ - however the computational time is reduced to $40 \%$. Of course with more processes (this case $N=2$ Only). The simulation method will be more practical.

FUTURE WORK

The only performance index we considered was the costhowever other performances may be considered such as maximum productivity, Minimal wear, etc. Also in the cost function the power consumption cost may be included this will certainly improve the total cost equation.

The system configuration with data base and the file constructions and soft-ware is a very interesting subject that we did not yet managed to design as integral system.

\section{REFERENCES}

1. J. HATVANY "WORLD SURVEY OF CAM"

Buttr-Worth Special Paplications, 1983.

2. MAGDA.. ZOHDI "APPLICATION OF. GEOMETRIC PROGRAMMING IN OPTIMIZATION OF TURNING OPERATION".

PEDAC, 1980, ALEX. EGYPT.

3. J. SOMLO "ON A NEW PRINCIPLE FOR ADAPTIVELY CONTROLLED M/C TOOLS" . IFAC, 1980, HUNGARY, BUDAPEST'.

4. S. SEKOLIC "OPTIMIZATION OF CUTTING CONDITIONS IN MILLING OPERATION BY SIMULATION". IFAC, 1980, HUNGARY, BUDAPEST.

5. MAROSSY AND SZASZ "ON AN EXPERIMENTAL SYSTEM FOR ADAPTIVE CONTROL. OPTIMIZATION OF M/C TOOLS". IFAC, 1980, HUNGARY, BUDAPEST. 6. ARSHINOV, ALEKSEC "METAL CUTTING THEORY AN CUTTING" TOOLS
DESIGN" MIR PUBLISHER. 1970.

7. DUFFIN R. "LINEARIZING GEOMETRIC PROGRAMS" SIAM, VOI. 12. NO. 2, 1970.

8. DEMBO "A COMPUTER PROGRAM FOR SOLVING GEOMETRIC PROGRAMMING PROBLEM" .

Report 72/89-1982. 